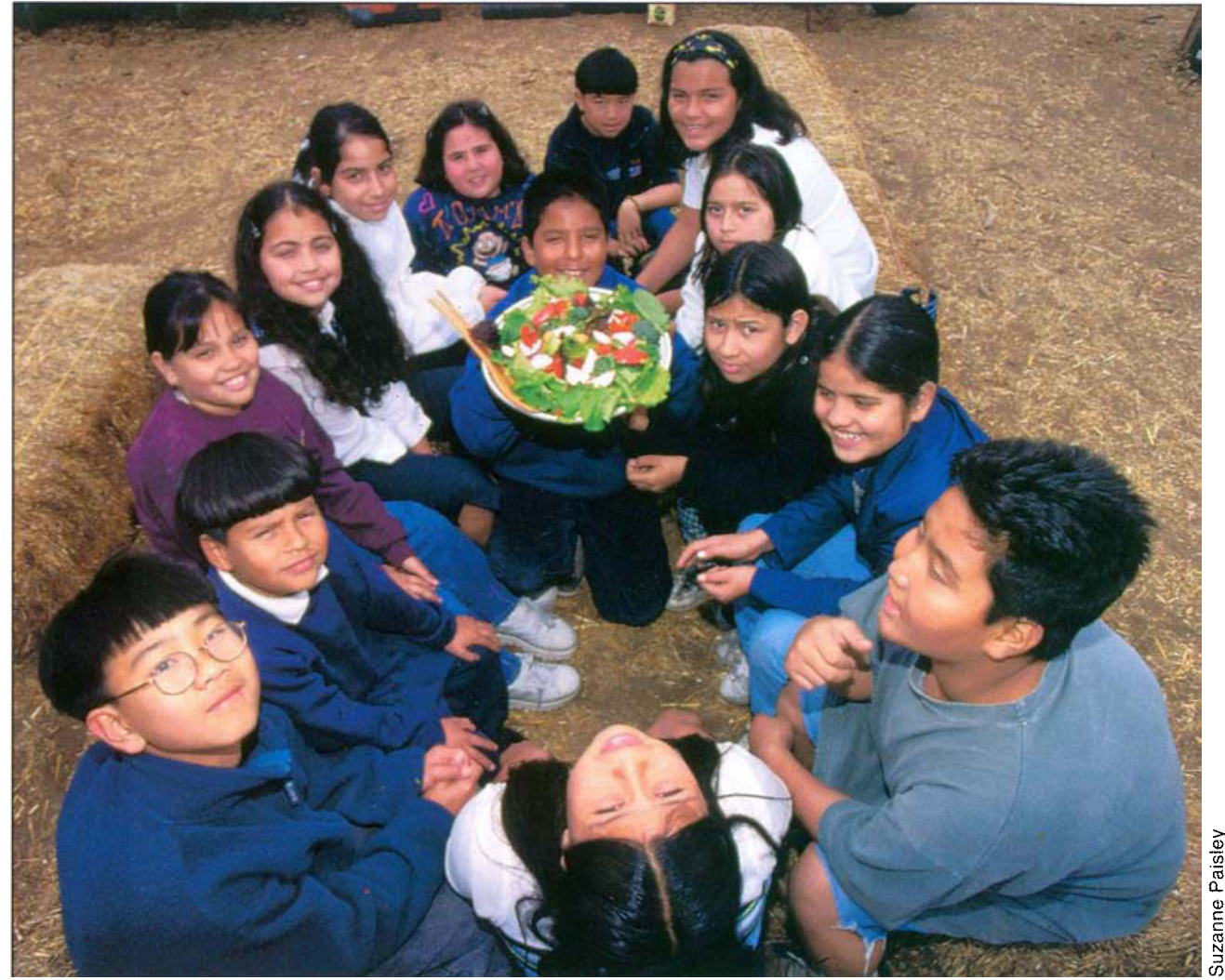

One study found that only $1 \%$ of U.S. children met the Food Guide Pyramid recommendations for the five major food groups. Gardens, such as this one at Vista Square Elementary School in San Diego County, help to teach kids important lessons about nutrition.

\section{School-based gardens can teach kids healthier eating habits}

\author{
Jennifer Morris a Marilyn Briggs 」 Sheri Zidenberg-Cherr
}

Fruits and vegetables are important in a child's diet because they provide the body with vitamins, minerals, fiber and several phytochemicals necessary for growth and development and health maintenance. However, a recent study found that only $7 \%$ of children aged 2 to 11 consumed the recommended two servings of fruits and three servings of vegetables each day. A limited number of nutrition education programs have been shown to improve dietary choices and selfreported health knowledge and behavior by school-aged children, at least in short-term results. An innovative approach is needed to motivate children to develop lifelong healthy eating habits. Our research shows that incorporating gardens into the school environment can reinforce nutrition lessons. Likewise, children who plant and harvest their own vegetables are more willing to taste and even like them. California Superintendent of Public Instruction Delaine Eastin has set a goal of "a garden in every school." As more of the state's farmland is lost to development, garden activities can reinforce good nutrition as well as teach California students about the value of agriculture.
$C_{c}$ urrent research shows that children's eating habits are not consistent with national recommendations (Dennison et al. 1998; KrebsSmith et al. 1996; McPherson et al. 1995; Muñoz et al. 1997; Reynolds et al. 1999). In general, children's energy intakes are not much higher than in past years. However, physical activity levels are lower, average fat intakes are still well above $30 \%$ of total calories, and fruit and vegetable consumption averages approximately 2.5 servings a day (Bronner 1996; McPherson et al. 1995).

A recent study found that only $1 \%$ of U.S. children met the Food Guide Pyramid recommendations for all five food groups (Muñoz et al. 1997). Another study found that only $7 \%$ of children ages 2 to 11 consumed the recommended two servings of fruits and three servings of vegetables each day (Krebs-Smith et al. 1996). Fruits and vegetables are important in a child's diet because they provide the body with nutrients such as vitamins, minerals, fiber and phytochemicals that are necessary for growth and development and health maintenance. Educators should provide children with ways to incorporate more healthful foods into their daily diets. A logical place to influence the knowledge and habits of children is in the classroom.

Nutrition education has been defined as "any set of learning experiences designed to facilitate the voluntary adoption of eating and other nutrition-related behaviors conducive to health and well-being" (SNE 1995). However, the term "behavior" does not solely imply nutrient intake. Nutritionrelated behaviors can refer to any activity related to the effects of nutrition education, such as consumption of a specific food group, food preferences, attitudes toward snack foods, food sanitation or food preparation techniques (Contento et al. 1995a). Nutrition education programs should strive to target a variety of health-related behaviors, not just nutrient intake. Not all school-based nutrition education programs are equally successful at promoting positive behavioral change. While some programs have shown some degree of success, much work is 

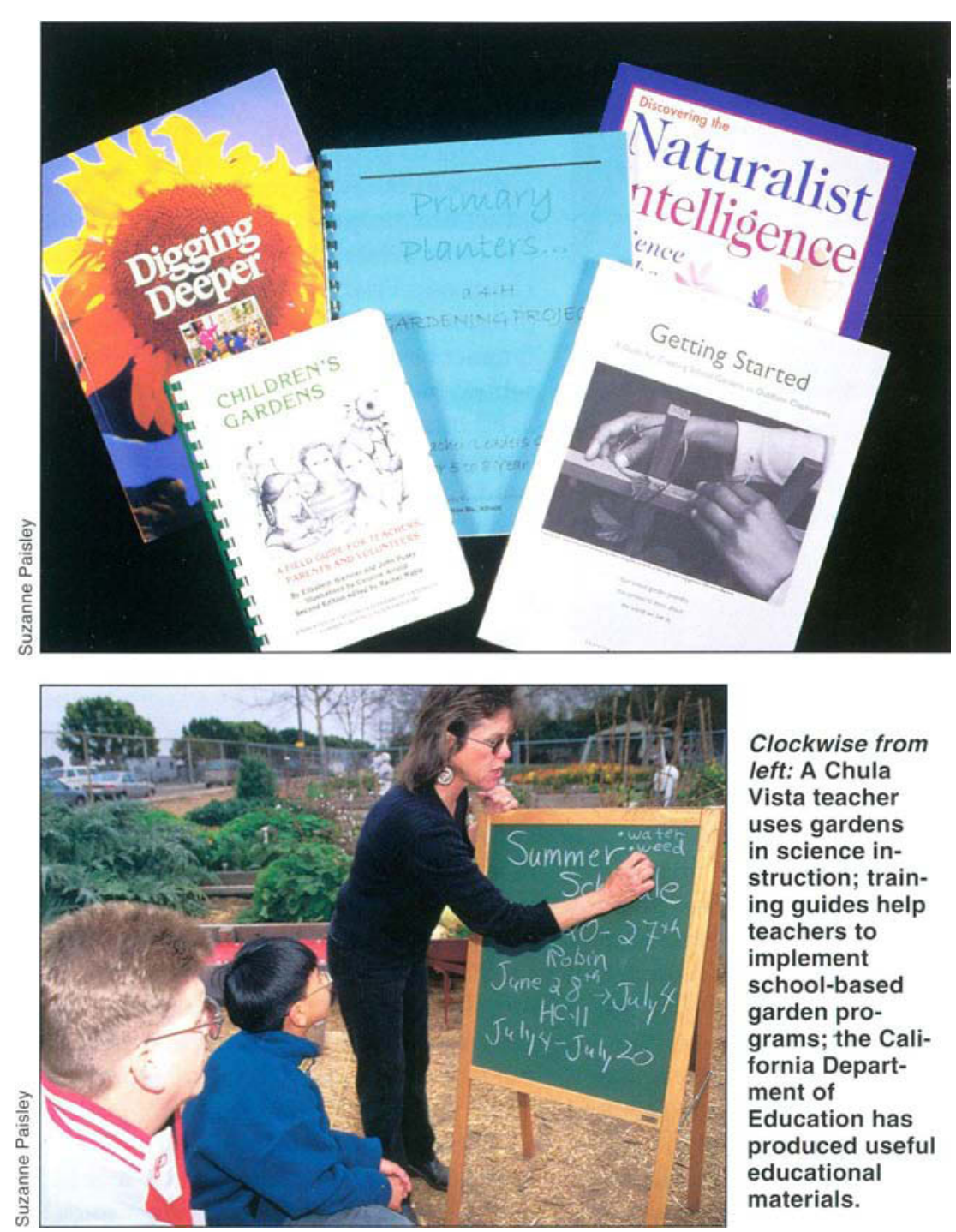

Clockwise from left: A Chula Vista teacher uses gardens in science instruction; training guides help teachers to implement school-based garden programs; the California Department of

Education has produced useful educational materials.

still needed to improve children's nutrition. The field of nutrition education is in need of an innovative approach. Incorporating school gardens into the curriculum is a possible solution, especially in California where agriculture is such an important part of our communities.

\section{Components of effective programs}

Research shows that for a program to be effective, it must be based on sound theoretical frameworks (Contento et al. 1995a). Modeling a program around a specific framework allows researchers to target and measure specific behaviors and motivating actions. A theoretical framework is valuable because it sets up guidelines for developing education lessons and assessment tools, ensuring the progression toward common goals.

Social cognitive theory.

While not used consistently, the model shown to be most effective when working with school-aged children is the social cognitive theory (SCT) (Contento et al. 1995b). SCT-based materials focus on three factors that are believed to be involved in altering health-related behaviors: personal (e.g., beliefs, values and knowledge); behavioral (e.g., skills needed to complete a task and monitoring habits); and environmental (e.g., influences, surroundings, peer modeling and parental support) (Bandura 1986). Programs based on this theory must alter all three of these factors in order to

\section{Bell Pepper, Red and Yellow}

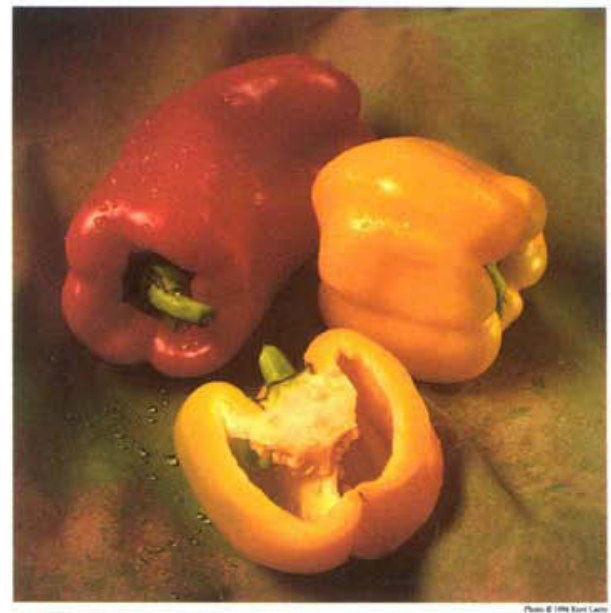

Chile de Campana,

Rojo y Amarillo

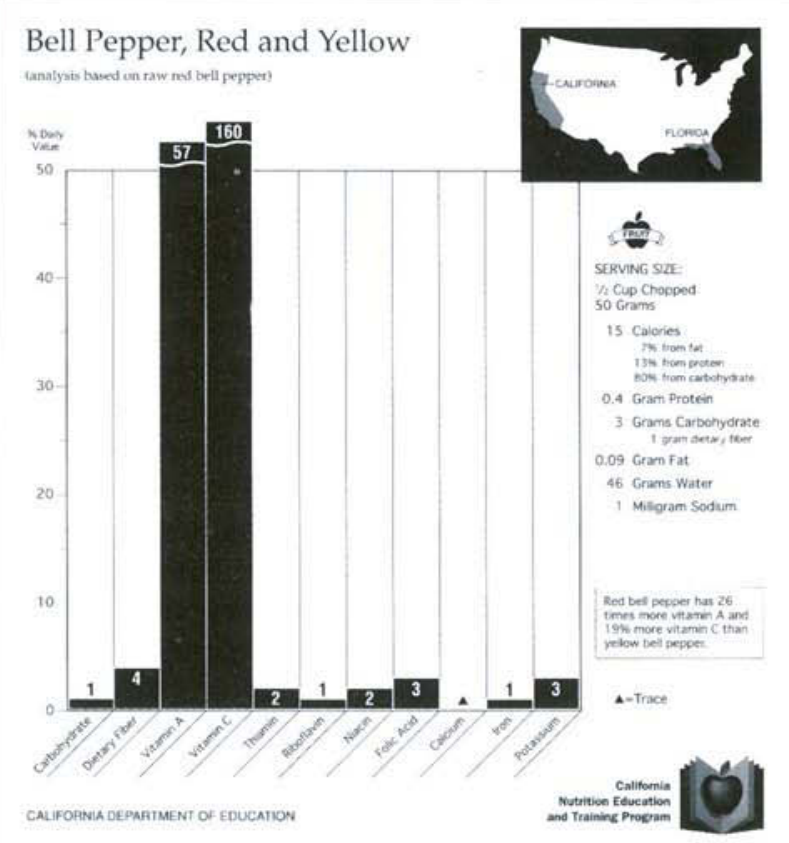

successfully change an individual's behavior. In addition, the SCT acknowledges that all three factors are continually interacting and that no single factor is influenced without influencing the others. Ultimately, programs based on the SCT acknowledge that young children are still greatly influenced by their surroundings.

Time and intensity. An effective nutrition education program is more than just theoretically based. Programs 


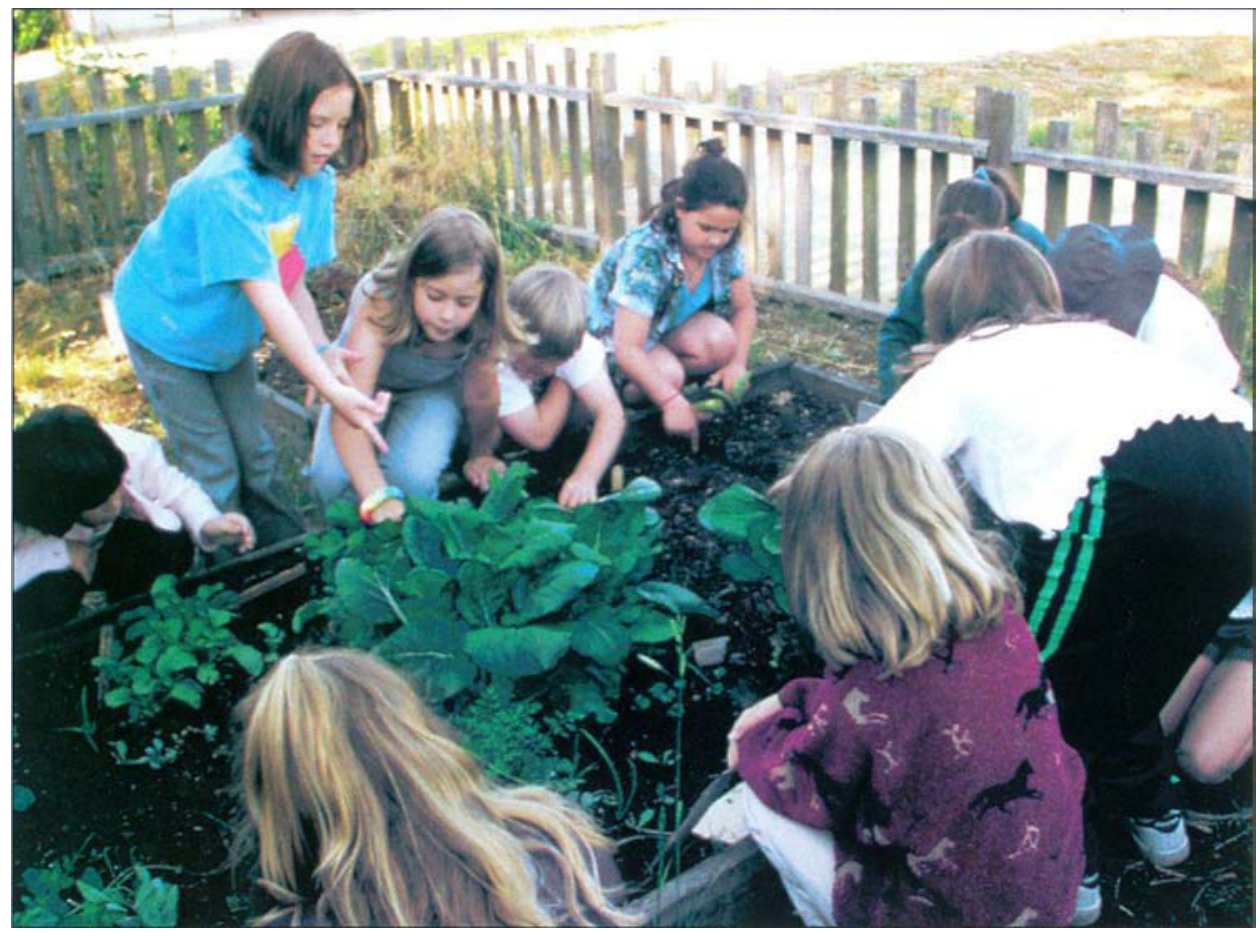

According to social cognitive theory, school-aged children will change health-related behaviors if instruction includes personal, behavioral and environmental influences. At Penngrove Elementary School, third-graders work their garden.

must be of adequate time and intensity. Some professionals have suggested that current school-based nutrition education programs are often unsuccessful because they are short in duration. Evidence suggests that approximately 15 hours of instruction are needed to change an individual's knowledge and 50 hours to change his or her behavior (Connell et al. 1985). However, teachers are often unable to provide that much time for nutrition and health-related topics and must integrate them into other subject areas. In addition, it may also be beneficial to alter the students' environment to continuously reinforce the material even when it's not being discussed in class. The level of intensity at which teachers implement lessons is also correlated with program effectiveness. Research shows that the more time and effort a teacher puts into nutrition lessons, the more beneficial those lessons will be to the students (Resnicow et al. 1992). The level of energy a teacher puts into a subject is often reflected in student knowledge gains and behavior improvements.

School involvement. Another factor that increases the effectiveness of a nutrition education program is the involvement of the entire school com- munity (Contento et al. 1995b). Students, teachers, food service workers, custodial staff and school administrators, as well as parents and other community members, must all work together to make the school a place that emphasizes healthy eating habits. By getting so many people involved, students are better able to appreciate the importance of what they are learning. Food service workers may begin to serve healthier meals showing that they too are committed to helping students choose healthy foods. They may also offer cafeteria tours or participate in classroom cooking lessons. The custodial staff may get involved by assisting with recycling and composting projects. Administrators may be able to allow students more time to eat and volved by asking students what they are learning about healthy lifestyles and adopting some practices at home.

Community involvement. Finally, the community can get involved by offering field trips to local grocery stores, farmer's markets or farms so children can learn where their food comes from. With so many farms scattered throughout the state, California schools have a wonderful advantage. It is important for children living in California to gain enjoy their meals. Parents could get in- an appreciation for all that the state's agriculture has to offer.

\section{Hearty Heart and Home Team}

One of the first large-scale nutrition education programs was conducted in the early 1980 s and used the Hearty Heart and Friends (HH) education program (Perry et al. 1985). The program consisted of a 10-week, 20-session, school-based curriculum that encouraged but did not require parental involvement. Sixteen third- and fourthgrade classrooms (eight intervention and eight control) participated in the study. The intervention incorporated the $\mathrm{HH}$ program during the fall, while the control classes received the school's "standard" nutrition education curriculum. Outcomes were measured prior to the program and after its completion 2 months later. The results showed that fruit and vegetable consumption increased while sugar and salt consumption decreased in the intervention group. In addition, the knowledge, attitudes and behaviors of the students improved, as demonstrated by responses to several questionnaires. However, no effort was made to determine the long-lasting effects of the program.

This study was later enhanced by adding a formal parental component and a 1-year follow-up (Luepker et al. 1988; Perry et al. 1989; Perry et al. 1985). In addition to the HH program, the authors introduced a home-based program called Home Team (HT). Materials were sent directly to the home to be completed by the children and parents. $\mathrm{HH}$ and $\mathrm{HT}$ were equivalent in content and duration (5 weeks). Thirty-two schools participated in the study and were randomly placed into one of the following groups: $\mathrm{HH}$ only, HT only, HH \& HT, or control (no program). Only third-grade students participated at each school. Data were collected before and after the intervention as well as 1 year later.

The results indicated a high rate of participation in both the $\mathrm{HH}$ and $\mathrm{HT}$ programs. Improvements in knowledge scores at the HH only and $\mathrm{HH} \&$ HT groups were significantly greater than improvements in the control group at the time of the post-test. 
While not consistently significant, students involved in the HT program (both alone or in combination with the $\mathrm{HH}$ program) did tend to have lower fat intakes following the intervention as shown by 24 -hour food consumption records. This trend diminished by the 1-year follow-up. The authors concluded that parental involvement was feasible and that adding such a component to a classroom-based nutrition education program may initiate changes in the child's dietary patterns.

\section{Know Your Body program}

There is concern that some of the variation in results obtained from nutrition education programs is due to the level of teacher implementation rather than the program itself. To study this further, Resnicow and colleagues assessed the feasibility of implementing the Know Your Body (KYB) program into the curriculum at five schools (Resnicow et al. 1992). KYB is an example of a nutrition education program that aimed to positively influence student health choices through schoolwide activities and environmental modifications.

The study population consisted of students in grades one through four, predominantly of lower socioeconomic status. Prior to the start, participating teachers received 1 to 2 days of training. The intervention consisted of in-class curriculum (one lesson per week for the entire year) as well as whole-school activities, including salad bars, fresh fruits and vegetables (e.g., changes in cafeteria environment). Teacher implementation was determined by responses to a self-reported questionnaire and ratings by a head teacher and project coordinator (teachers were rated as "low," "medium" or "high" implementers).

Results suggested a dose-response relationship between teacher implementation and several measured indices. The students of high-implementation teachers improved their total plasmacholesterol levels, systolic blood pressure, intake of vegetables, and health knowledge as compared to students of low-implementation teachers. It is clear that the intensity at which a teacher implements lessons is re- flected in student improvements.

\section{Trial for Cardiovas- cular Health}

With all of this knowledge, several investigators designed yet another nutrition education program, the Child and Adolescent Trial for Cardiovascular Health (CATCH) (Luepker et al. 1996). CATCH is one of the largest and most intensive schoolbased health education programs to date, with 96 public schools at four sites across the country participating. The schools were randomly assigned to either an intervention or control group. The students at the intervention schools were exposed to activities in school and at home. The school activities included modifications to the school meal programs and time spent in physical activity as well as classroom lessons throughout the year.

Results indicated a significant improvement in the health-knowledge scores of the students in the intervention group as compared to those in the control group. No significant differences were seen in total blood cholesterol levels or systolic blood pressure between the two groups. However, fat intake was significantly lower and the time engaged in moderate to vigorous physical activity was significantly higher among students at the intervention sites.

Further research is needed to determine the long-term effects of such a program. In addition, efforts must be made to control for the level of teacher implementation when evaluating nutrition education programs. While the potential value of multifaceted nutrition education programs within schools has been demonstrated, schools still must grapple with how to

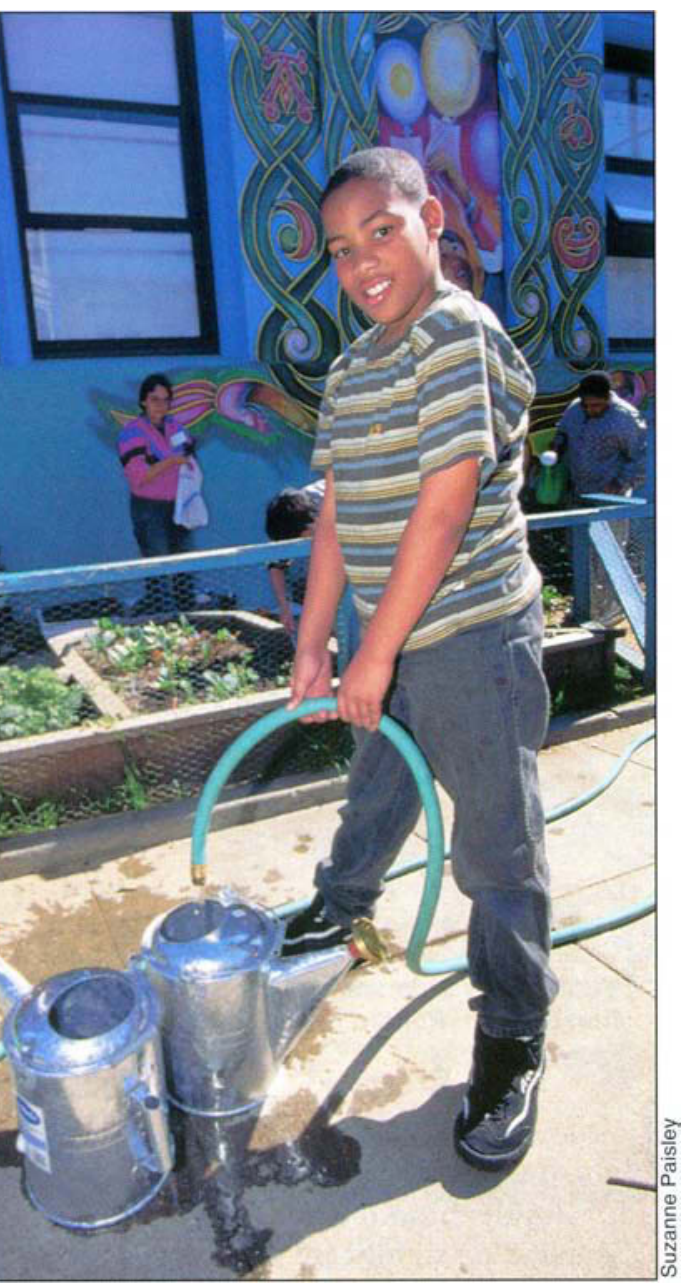

More than 1,800 California schools (out of about 8,500 total) have gardens, and nearly all may have at least one by 2025. A UC 4-H research project is evaluating the role of school gardens in education, including at Cesar Chavez Elementary School in San Francisco.

get high levels of student, teacher, school, parent and community involvement and implementation in nonstudy settings.

\section{The Gimme 5 program}

The final two programs focus specifically on increasing children's fruit and vegetable consumption. One study conducted by Domel and colleagues (1993) reported on the development and evaluation of the Gimme 5 program. This program was designed to increase fruit and vegetable consumption among fourth- and fifthgrade students. Data was collected in food diaries as well as knowledge and preference questionnaires before and after the intervention. Classroom teachers taught all lessons after participating in a training program. Following the intervention, the change in nutrition-knowledge scores was sig- 


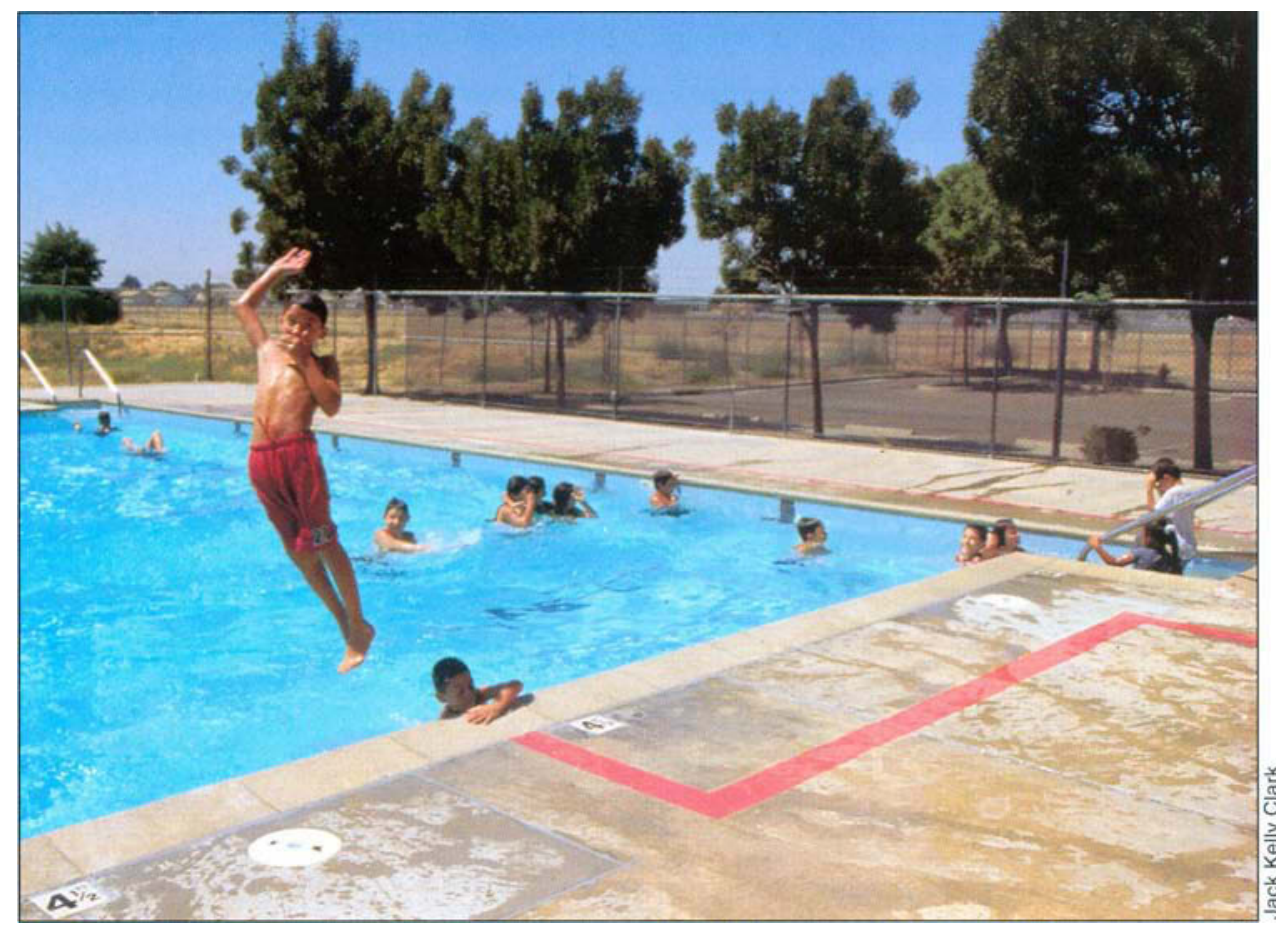

While many kids are "couch potatoes," schools can play a role in encouraging healthier lifestyles. In Parlier, kids get some exercise at the city pool.

nificantly greater at the intervention site than the control site.

Results from the food diaries showed no significant difference in total fruit and vegetable intake between the intervention and control sites. However, the intervention group increased consumption of fruit, while the control group increased their consumption of vegetables. French-fried potatoes were the vegetable recorded as most often consumed by both groups. Lastly, the program resulted in improved preferences - one indicator of dietary behavior - for fruit and vegetable snacks at the intervention site. This change in preference, however, did not account for changes in consumption. In this specific study, there was no association between the consumption patterns of children and the exposure to a short-term nutrition education program.

\section{The 5-A-Day Power Plus}

The goal of improving children's fruit and vegetable intake was revisited with a more intensive nutrition education program called the 5-A-Day Power Plus program. This program was multifaceted and implemented in fourth-grade classrooms at 20 schools in St. Paul, Minn. (Perry et al. 1998). It consisted of in-class, behavior-based lessons with two lessons taught each week for eight weeks; a parental component, with information and food sent home; involvement of the school's food service staff; and participation by the local agricultural industry, which provided additional fruits and vegetables for the program. After the schools were matched, they were randomly assigned into either the intervention or control group. Measurements included 24-hour dietary recalls, lunchroom observations, a health behavior questionnaire and a parental questionnaire.

Results from the 24-hour recalls and lunchroom observations indicated an increase in the consumption of fruits and a decrease in intake of fats by students at the intervention sites. The health behavior questionnaire showed an improvement in students' self-reported ability to ask for or consume fruits and vegetables within the intervention group. The parental questionnaire showed an increased awareness of the 5-A-Day program by the parents of students at the intervention site. In conclusion, this program resulted in an improvement in fruit intake and self-reported health knowledge and behavior by the children involved. This program was highly intense, involving collaboration at a variety of levels inside and outside the school environment. Unfortunately these intensive programs, while generally successful, are often unrealistic for individual teachers to bring into their own classrooms.

\section{Garden-enhanced education}

Despite what we know about the components of a successful nutrition education program, not all show consistent long-term success. As a result, many educators are aware that nutrition education is in need of an innovative approach. We believe that adding a vegetable garden to a nutrition curriculum is an innovative approach that meets the needs of California.

There are many potential benefits to the inclusion of a vegetable garden within a classroom setting. A garden enhances the modeling of the program around the SCT. Gardening not only provides opportunities to improve student knowledge and skills related to healthy eating, but it also significantly enhances their awareness of the environment. Vegetable gardens provide continuous visual reinforcement of nutrition lessons, even on days when nutrition is not being taught. Another benefit is the increased availability and accessibility of fresh fruits and vegetables. If the garden produces enough, foods can be served as part of school lunch for the whole school to enjoy.

Gardens also provide students with hands-on experience throughout the growing, harvesting and preparation of common and uncommon foods. This allows the students to get involved in the process of preparing their own foods. In addition, gardens provide a wonderful opportunity for food service staff, parents and community members to become involved. Garden activities can teach students more about the value of the agricultural land in their community and where their food comes from. They can be used to teach a variety of subjects, including math, language arts, science, social science, and health. Nonetheless, very few well-designed studies had been conducted to deter- 
mine the effect of gardening on the health-related behaviors of children.

Gardens and diet. Our research group recently investigated the hypothesis that combining the harvest of a vegetable garden with nutrition lessons would have a greater effect on children's dietary behaviors than nutrition lessons alone. We conducted a pilot study to evaluate the initial feasibility of implementing and evaluating a garden-enhanced nutrition education program within a school setting (Morris et al. [in press]). This study was conducted with first-graders from a control $(n=49)$ and intervention site $(n=48)$. Students at the intervention site were exposed to several nutrition lessons throughout the school year in combination with fall and spring vegetable gardens, while the control site received no formal nutrition or gardening education. Results showed a significant improvement in willingness to taste vegetables among students at the intervention site. We concluded that it is possible to implement and evaluate such a program within school-year constraints.

Once we determined the feasibility, we developed a more comprehensive nutrition education curriculum designed to improve the nutrition knowledge and vegetable preferences of all elementary school-aged children. Vegetable preferences were chosen as a predictor of food intake because preference must be changed in order to improve overall consumption patterns. The curriculum was developed around the SCT and consisted of nine nutrition lessons with complementary gardening activities. Following each lesson, students were sent home with a family newsletter to encourage parental involvement and discussion. The curriculum lessons were designed with standards for the core subject areas in mind, to assist in the teaching of math, science, language arts and other subjects. The lessons were repeatedly field-tested in several fourth-and fifth-grade classrooms and revised until no further changes were necessary. We also developed a nutritionknowledge questionnaire consisting of 30 multiple-choice questions, and a vegetable-preference survey that gave students the opportunity to taste and rate six different vegetables on a fivepoint scale.

The formal evaluation of the curriculum took place within a Northern California school district (Morris and Zidenberg-Cherr, unpublished data). Fourth-grade students $(n=215)$ from three different schools participated in this study. One school was designated as the control site and received no formal nutrition or gardening education (CO). Another school was designated as the classroom-based nutrition education site and received only the inclass nutrition lessons (NL). The third school was designated as the gardenbased nutrition education site and received both the in-class nutrition lessons and the garden activities (NG).

Students at all three sites completed both the nutrition-knowledge questionnaire and the vegetable-preference survey before and after the intervention, and 6 months later. Following the intervention, nutrition-knowledge scores at the NL and NG sites were greater than those at the CO site. These improvements were still evident 6 months later. Student preferences for carrots and broccoli were higher at the NL and NG sites than the CO site, while preferences for zucchini and snow peas were higher only at the NG site. Most improvements at the NG site were retained at the 6-month follow-up.

We conclude that this gardenenhanced nutrition education curriculum is an effective tool for improving the nutrition knowledge and vegetable preferences of elementary school-aged children. Additional work is needed to assess the effect of such a curriculum on the fruit and vegetable intake patterns of children.

\section{Future in focus: Implications for nutrition education}

Educating children about nutrition is critical for dietary behavior patterns to improve. Many education programs have attempted to incorporate nutrition into a comprehensive school health program. Some have observed changes in knowledge and only a limited number of programs have resulted in behavioral changes.
The California Department of Education and the California Department of Health Services report, Building Infrastructures for Coordinated School Health: A California Blueprint, proposes a framework for implementing coordinated school health and is consistent with the Centers for Disease Control recommendations in the Fit, Healthy and Ready to Learn policy guide (CDHS/CDE 2000; NASBE 2000). The CDE's Nutrition Services Division is implementing nutrition education through SHAPE (Shaping Health as Partners in Education) California. The California Children's 5 a Day and California Project LEAN from the Department of Health Services has developed

\section{Gardening not only} provides opportunities to improve student knowledge and skills related to healthy eating, but it also significantly enhances their awareness of the environment. Vegetable gardens provide continuous visual reinforcement of nutrition lessons, even on days when nutrition is not being taught.

and is implementing programs for upper elementary and high school students. Realistically, nutrition education will have to be integrated into other subject areas in order to be consistent with the current standardbased educational framework.

There are several benefits of adding fruit and vegetable gardens to the classroom curriculum. As shown by our research, children who plant and harvest their own vegetables are more willing to taste and even like them than children who did not participate. With all of the fast food options avail- 


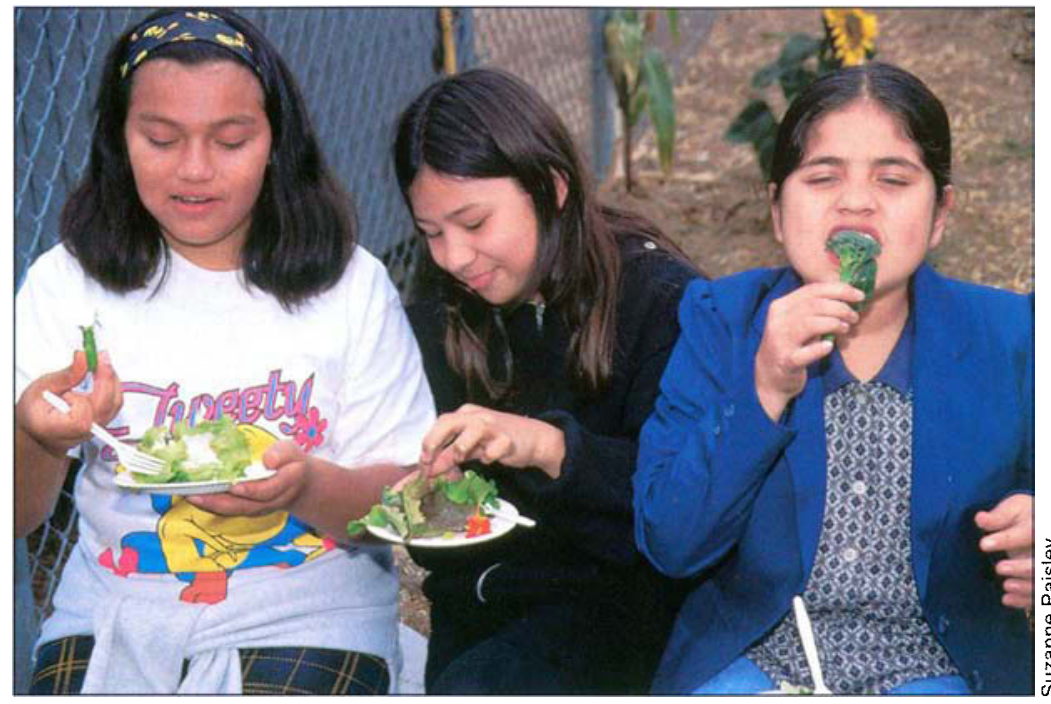

Research is demonstrating that children who grow their own food at school are more willing to taste, and even enjoy, healthy fruits and vegetables.

able, children find it increasing difficult to eat five servings of fruits and vegetables every day.

California Superintendent of Public Instruction Delaine Eastin has set a goal of "a garden in every school." She, along with many others, has long recognized the value gardens have in education. Currently over 1,800 schools (out of about 8,500 ) have a garden and we anticipate that by 2025 close to every school will have a garden. The California Department of Education implements nutrition education in part through their gardenenhanced nutrition education projects. UC plays an active role in meeting one of the key challenges to incorporating garden-based learning into nutrition education - teacher training. Specifically, the UC Davis Children's Garden program provides workshops for teachers on specific garden-related topics. Research conducted by UC academics is essential for the promotion and implementation of nutrition education in $\mathrm{K}-12$ education. For effective policy recommendations to be made, key stakeholders such as the state Legislature must be made aware of the impact that such programs can have on children's health-related behaviors and academic achievement.

Teaching the importance of agriculture is especially important to the children of California. Every year more farmland is developed, leaving less land on which to grow food. Today's children will be voters and policy-makers in 2025, and they must understand the importance of conserving farmland. School-based gardens provide wonderful opportunities to teach children about sustainable food systems and improved food security, both of which will become increasingly important as the state's population increases.

Gardens may be the key to successful nutrition education programs, not just in California but across the nation. Much research work is still needed, but the results to date imply significant long-term benefits for the health and well-being of our children.

I. Morris was doctoral student in Department of Nutrition, UC Davis; M. Briggs is Assistant Superintendent of Public Instruction, California Department of Education; and S. Zidenberg-Cherr is Nutrition Science Specialist, Department of Nutrition, UC Davis.

\section{References}

Bandura A. 1986. Social Foundations of Thought and Action: A Social Cognitive Theory. Englewood Cliffs, NJ: Prentice-Hall, Inc. $240 \mathrm{p}$.

Bronner YL. 1996. Nutritional status outcomes for children: Ethnic, cultural and environmental contexts. J Am Diet Assoc 96(9):891-900, 3

[CDHS/CDE] California Department of Health Services and California Department of Education's School Health Connections. 2000. Building Infrastructures for Coordinated School Health: A California Blueprint January $10 \mathrm{p}$.

Connell DB, Turner RR, Mason EF. 1985. Summary of findings of the school health education evaluation: Health promotion effectiveness, implementation and costs. J Sch Health $55(8): 316-21$

Contento I, Balch GI, Bronner YL, et al. 1995a. Theoretical frameworks or models for nutrition education. J Nutr Educ 27(6):287-90.
Contento I, Balch Gi, Bronner YL, et al. 1995b. Nutrition education for school-aged children. J Nutr Educ 27(6):298-311.

Dennison BA, Rockwell HL, Baker SL. 1998. Fruit and vegetable intake in young children. J Am Coll Nutr 17(4):371-8.

Domel SB, Baranowski T, Davis $\mathrm{H}$, et al. 1993. Development and evaluation of a school intervention to increase fruit and vegetable consumption among fourth - and fifthgrade students. J Nutr Educ 25(6):345-9.

Krebs-Smith SM, Cook A, Subar AF, et al, 1996. Fruit and vegetable intakes of children and adolescents in the United States. Arch Pediatr Adolesc Med 150(1):81-6.

Luepker RV, Perry CL, McKinlay SM, et al. 1996. Outcomes of a field trial to improve children's dietary patterns and physical activity: The Child and Adolescent Trial for Cardiovascular Health. JAMA 275(10):768-76.

Luepker RV, Perry CL, Murray DM, Mullis R. 1988. Hypertension prevention through nutrition education in youth: A school-based program involving parents. Health Psychol 7(Suppl.):233-45.

McPherson RS, Montgomery DH, Nichaman MZ. 1995. Nutritional status of children: What do we know? J Nutr Educ 27(5):225-34

Morris JL, Neustadter A, Zidenberg-Cherr $S$. (In press). Determining the feasibility and effectiveness of a garden-enhanced nutrition education program with first-grade school children. Cal Ag.

Muñoz KA, Krebs-Smith SM, BallardBarbash R, Cleveland LE. 1997. Food intakes of U.S. children and adolescents compared with recommendations. Pediatrics 100(3):323-9.

[NASBE] National Association of State Boards of Education. 2000. Fit, Healthy, and Ready to Learn: A School Health Policy Guide January. $19 p$.

Perry CL, Bishop DB, Taylor G, et al. 1998. Changing fruit and vegetable consumption among children: The 5-a-Day Power Plus program in St. Paul, MN. Am J Public Health 88(4):603-9.

Perry CL, Luepker RV, Murray DM, et al. 1989. Parent involvement with children's health promotion: A 1-year follow-up of the Minnesota Home Team. Health Educ $Q$ 16(2):171-80.

Perry CL, Mullis RM, Maile MC. 1985. Modifying the eating behavior of young children. J Sch Health 55(10):399-402.

Resnicow K, Cohn L, Reinhardt J, et al 1992. A 3-year evaluation of the Know Your Body program in inner-city school children. Health Educ Q 19(4):463-80.

Reynolds KD, Baranowski T. Bishop DB, et al. 1999. Patterns in child and adolescent consumption of fruit and vegetables: Effects of gender and ethnicity across four sites. $J$ Am Coll Nutr 18(3):248-54.

[SNE] Society for Nutrition Education. 1995. Joint position of SNE, American Dietetic Association and American School Food Service Association: School-based nutrition programs and services. J Nutr Educ 27(6):58-61. 